\title{
Conflitos e sentimentos de mulheres portadoras de HIV/Aids: um estudo bibliográfico
}

\author{
FEELINGS AND CONFLICTS OF WOMEN LIVING WITH HIVIAIDS: \\ A LITERATURE REVIEW \\ CONFLICTOS Y SENTIMIENTOS DE LAS MUJERES PORTADORAS DE VIH/SIDA: \\ UNA INVESTIGACIÓN BIBLIOGRÁFICA
}

\author{
Maria Luciana Botti' ${ }^{1}$, Maria Angélica Pagliarini Waidman², Sonia Silva Marcon ${ }^{3}$, Maria José Scochi $^{4}$
}

\begin{abstract}
RESUMO
Pesquisa bibliográfica que buscou identificar como os conflitos e sentimentos das mulheres portadoras de HIV/Aids são abordados na literatura nacional e os caminhos propostos para uma abordagem de cuidado integral. Os dados foram coletados em novembro de 2006, na base de dados LILACS, utilizando as palavras-chave: mulheres, sentimentos, HIV, Aids, sofrimento, depressão e medo e como critério de inclusão o fato de os estudos terem sido divulgados nos últimos cinco anos. A amostra ficou constituída de catorze pesquisas (quatro teses, duas dissertações e oito artigos). O método de análise de conteúdo permitiu identificar três categorias temáticas: o olhar do pesquisador, o que seu olhar identifica e o seu olhar para além do corpo físico - as quais revelam a necessidade de abordar as mulheres considerando todo o seu contexto enquanto ser humano, incluindo questões de vulnerabili-dade, ideologia social de gênero, promoção da auto-estima e exercício da cidadania.
\end{abstract}

\section{DESCRITORES}

Mulheres.

Emoções.

HIV.

Síndrome de imunodeficiência adquirida.

Serviços de saúde da mulher.

\begin{abstract}
This is a literature review with the purpose to identify how the conflicts and feelings of women living with HIV/AIDS are addressed in the national literature, and the proposed pathways for an integral care approach. Data were collected in November, 2006, in the LILACS database, using the following keywords: women, feelings, HIV, AIDS, suffering, depression and fear. The inclusion criterion was that these studies should have been published in the past five years. The sample was made up of 14 studies (four dissertations, two theses and eight articles). The content analysis method allowed for the identification of three thematic categories: the researcher's perspective, what their perspective identifies and their perspective beyond the physical body - which reveal the necessity of addressing women considering their whole context as human beings, including issues of vulnerability, social gender ideology and the promotion of self-esteem and citizenship.
\end{abstract}

\section{KEY WORDS}

Women.

Emotions.

HIV.

Acquired immunodeficiency syndrome. Women's health services.

\section{RESUMEN}

Se trata de una investigación bibliográfica que buscó identificar como los conflictos y sentimientos de las mujeres portadoras de HIV/SIDA son abordados en la literatura nacional y los caminos propuestos para un abordaje de cuidado integral. Los datos fueron recolectados en noviembre de 2006, en la base de datos LILACS, utilizando las palabras clave: mujeres, sentimientos, HIV, SIDA, sufrimiento, depresión y miedo y como criterio de inclusión la divulgación del estudio en los últimos cinco años. La muestra fue constituida de catorce investigaciones (cuatro tesis, dos disertaciones y ocho artículos). El método de análisis de contenido permitió identificar tres categorías temáticas: la perspectiva del investigador, lo que su perspectiva identifica y su perspectiva más allá del cuerpo físico - las cuales revelan la necesidad de abordar a las mujeres considerando todo su contexto en cuanto ser humano, incluyendo cuestiones de vulnerabilidad, ideología social de género, promoción de la autoestima y ejercicio de la ciudadanía.

\section{DESCRIPTORES}

Mujeres.

Emociones.

VIH.

Síndrome de inmunodeficiencia adquirida. Servicios de salud para mujeres.

1 Enfermeira do Ambulatório Municipal de DST/HIV/Aids. Secretaria Municipal de Saúde de Maringá. Mestre em Enfermagem. Maringá, PR, Brasil. malubotti@yahoo.com.br 22Enfermeira. Doutora em Filosofia da Enfermagem. Professora do Departamento de Enfermagem Universidade Estadual de Maringá Maringá, PR, Brasil. angelicawaidman@hotmail.com ${ }^{3}$ Enfermeira. Doutora em Filosofia da Enfermagem. Professora do Departamento de Enfermagem, Coordenadora do Mestrado em Enfermagem, Universidade Estadual de Maringá. Maringá, PR, Brasil. ssmarcon@uem.br ${ }^{4}$ Enfermeira. Doutora em Saúde Pública. Professora do Departamento de Enfermagem, Universidade Estadual de Maringá. Maringá, PR, Brasil. mjscochi@uem.br 


\section{INTRODUÇÃO}

Compreender a interface entre ciência e cuidado representa aceitar a existência de possibilidades frente a paradigmas comumente tratados como independentes: de um lado a ciência, condicionada aos ditames positivistas e distanciada da inserção na prática cotidiana do assistir em enfermagem; e do outro, o cuidado, justificado pelos preceitos filosóficos humanistas, o qual, apesar de proclamado como objeto da ação da enfermagem, estabelece-se como conhecimento empírico, permanecendo em uma dimensão inferior ao saber científico.

Essa segregação entre ciência e cuidado dificulta a compreensão de fenômenos sociais complexos, como, por exemplo, a epidemia da aids, caracterizada deste modo por poder ser concebida ao mesmo tempo como causa e efeito das relações sociais, pois revelou preconceitos e estigmas, associando a condição sorológica para o HIV à incapacidade e à segregação social de homens, mulheres e crianças. estranheza e são desvalorizados no meio científico; d) a aproximação com a realidade pode colaborar para o afastamento do pesquisador das temáticas que possam incluílo como indivíduo que possua vulnerabilidades.

Outra motivação, não menos significativa para a realização deste estudo, surgiu a partir da escuta das mulheres que vivem e convivem com o HIV. No atendimento a estas mulheres, observa-se que os conflitos relatados, apesar de serem subjetivos, estão vinculados à condição de ser portadora do vírus numa perspectiva além da existência do vírus no sangue, ou seja, a situação sorológica ultrapassa as questões biofisiológicas, transcendem o corpo, envolvem a psique, ou seja, a força dinâmica e energética da existência humana - a alma dessas mulheres.

Nesta perspectiva, surge o interesse em verificar a existência de trabalhos e pesquisas que, além das questões epidemiológicas, fisiopatológicas e de tratamento, abordem os aspectos psicossociais vivenciados pelas portadoras do HIV/aids, a partir da seguinte questão norteadora: Quais são os subsídios que a produção científica da área de saúde oferece em relação aos conflitos e sentimentos das mulhe-res portadoras de HIV/aids que possam propiciar um olhar para além do corpo físico?

Com a intenção de responder a tal questão propôs-se o desenvolvimento deste estudo, com os objetivos de: a) identificar como as publicações científicas brasileiras da área de saúde tratam os conflitos e sentimentos das mulheres portadoras de HIV/aids, para conhecer os caminhos que possibilitem uma abordagem de cuidado a essas mulheres; b) conhecer as teorias e os métodos utilizados pelos pesquisadores nos estudos dessa temática, para identificar direcionamentos que possam envolver o cuidado para além do corpo físico das mulheres com HIV/Aids. possibilitam a sua socialização, também fazendo aproximações necessárias para a prevenção da transmissão do HIV e controle da aids.

A presença do vírus HIV e da aids, transcorridas quase três décadas, ainda causa diferentes reações, principalmente em relação aos aspectos psicossociais, pois requer amplas discussões, além das questões biofisiológicas amplamente pesquisadas e divulgadas. A produção científica sobre o HIV e a aids vem ocupando lugar de destaque em relação às inúmeras publicações em periódicos nacionais e internacionais.

A partir de alguns questionamentos e reflexões a respeito de como a ciência, ou ainda os pesquisadores, têmse inserido na produção científica sobre o tema Aids, surgiu o interesse em desenvolver o presente artigo, que se justifica por quatro considerações: a) os interesses que levam o pesquisador a direcionar seu trabalho para aids; $b$ ) as áreas com enfoque biologista têm maior aproximação ao tema, ao comparar-se com as áreas que tratam das ciências sociais e humanas; c) os aspectos psicossociais, ao serem abordados por pesquisas da área da saúde, causam

\section{MÉTODO}

Por permitir o aprofundamento em leituras a respeito do tema de forma sistematizada e crítica, optou-se pela utilização da pesquisa bibliográfica como método de investigação para responder à questão norteadora. A pesquisa bibliográfica geralmente é empregada para explicar um problema a partir de referências teóricas publicadas em documentos, buscando conhecer ou analisar as contribuições culturais ou científicas existentes sobre determinado assunto ou tema ${ }^{(1)}$.

Uma das vantagens da pesquisa bibliográfica reside no fato de permitir ao pesquisador a cobertura de uma gama de fenômenos maior do que aquela que poderia atingir se pesquisasse diretamente. Para tanto alguns passos são indicados: 1) busca do material nos catálogos das bibliotecas; 2) seleção dos textos de acordo com os objetivos; 3) leitura do texto; 4) anotações somente depois de ter lido
Conflitos e sentimentos de mulheres portadoras de HIVIAids: um estudo bibliográfico Botti ML, Waidman MAP, Marcon SS, Scochi MJ 
o texto criticamente; 5) transcrição dos dados exatos e úteis em relação ao tema levantado; 6) registro de qualquer idéia crítica ou conjectura pessoal que venha a emergir no decorrer da leitura, para posterior verificação e reflexão; 7) correta citação das fontes no relatório de pesquisa, evitando o problema de uso indevido do material, que caracteriza a violação das normas nacionais e internacionais de direitos autorais $^{(2)}$.

A seleção do material se deu a partir da busca sistemática na base de dados da Literatura Latino-Americana e do Caribe em Ciências da Saúde (LILACS), no mês de novembro de 2006, a partir das palavras-chave: mulheres, sentimentos e aids; mulheres, sentimentos e HIV; mulheres, conflitos e aids; mulheres sofrimento e aids; mulheres, depressão e aids; mulheres, medo e Aids e utilizando como critério o fato de os estudos terem sido divulgados nos últimos cinco anos. Foram encontradas 419 publicações.

O resultado inicial foi analisado e selecionado, retirando-se da amostra os itens que não correspondessem a pesquisas científicas ou estivessem repetidos nos diferentes grupos de palavras-chave pesquisados. A seguir, organizouse um banco de dados contendo as referências bibliográficas e os resumos de cada publicação científica, conforme a disponibilidade no LILACS.

Esse material sofreu nova seleção, por meio de leitura e análise, para os seguintes critérios de inclusão das produções científicas: a) abranger o tema: conflitos e sentimentos das mulheres portadoras de HIV e aids; b) ser produção nacional; c) caracterizar-se como artigo publicado em periódico indexado, dissertações de mestrado e teses de doutorado.

A amostra final, após as sucessivas seleções, constituise de catorze pesquisas, sendo quatro teses de doutorado, duas dissertações de mestrado e oito artigos publicados em periódicos nacionais. Para organização dos resultados gerou-se uma planilha de registros, contendo identificação, objetivos, referencial teórico, referencial metodológico, situação encontrada, fatores associados e respostas, conforme exemplificado no Quadro 1 (Anexo), e que auxiliou na posterior análise de conteúdo.

A leitura, classificação e registro das informações e conteúdos contemplaram: a) dados de identificação: título, autor(es), a escola onde se deu a defesa ou periódico em que o material foi publicado, ano de defesa ou da publicação; b) objetivos; c) referenciais teóricos; d) referenciais metodológicos; e) contextualização, ou seja, situações vivenciadas pelas mulheres e fatores associados a estas vivências; f) respostas à questão norteadora.

Foi utilizada a análise de conteúdo, pois esta se caracteriza como um conjunto de instrumentos metodológicos que pode ser aplicado a elementos de comunicação extremamente diversificados, visando manipular mensagens para evidenciar referências que permitam inferir sobre uma outra realidade que não a da mensagem ${ }^{(3)}$.
Este tipo de análise tem duas funções, que podem ou não se dissociar quando colocadas em prática. A primeira diz respeito à função heurística, ou seja, a análise de conteúdo enriquece a tentativa exploratória e aumenta a propensão à descoberta; e a segunda se refere à administração da prova, em que hipóteses sob a forma de questões ou de afirmações provisórias servem de diretrizes, apelando para o método de análise de uma confirmação ou de uma informação ${ }^{(3)}$.

Neste artigo, a análise de conteúdo recorre às duas funções, pois tanto se apresenta como processo exploratório da pesquisa bibliográfica como estabelece pressuposições à questão norteadora do estudo.

\section{RESULTADOS E DISCUSSÃO}

A análise dos dados possibilitou o encontro de temas relevantes que fundamentaram a elaboração das categorias temáticas: o olhar do pesquisador, como o pesquisador olha, o que o olhar do pesquisador identifica, e o olhar para além do corpo físico.

\section{O olhar do pesquisador}

- Primeira rubrica de análise - $A$ vulnerabilidade relacionada ao feminino e às mulheres com HIV/AIDS a partir da perspectiva de gênero.

A vulnerabilidade feminina tem sido assinalada pela subordinação da mulher ao desejo masculino, sendo determinada por relações conflituosas com sua própria sexualidade. A identidade feminina constrói-se a partir de determinantes culturais e sociais que reforçam o amor como uma espécie de proteção, estabelecendo riscos frente às doenças sexualmente transmissíveis e à Aids. Neste aspecto, pode-se verificar a preocupação dos pesquisadores em entender a vulnerabilidade feminina, ilustrada pelos objetivos de alguns dos estudos: Descrever como as mulheres portadoras do HIV percebem sua vulnerabilidade na provável época da infecção e compreender as dificuldades de prevenção da transmissão sexual do HIV antes e depois do diagnóstico(4); Caracterizar a vulnerabilidade individual em relação às práticas e atitudes sobre a sexualidade de estudantes do sexo feminino, do primeiro ano dos cursos de uma universidade na cidade do Rio de Janeiro, visando subsidiar intervenções preventivas à transmissão do HIV(5); Percepção do risco de infecção em mulheres infectadas pelo HIV ${ }^{(6)}$.

As relações e os papéis sociais de gênero, de certa forma, determinam à saúde e a doença das mulheres, pois influenciam o seu comportamento diante do auto-cuidado. A maternidade, por exemplo, afirmada como um elemento muito forte da cultura e identidade feminina pela sua ligação com o corpo e com a natureza, em tempos de Aids, caracteriza-se pelo temor e culpabilidade. Várias são as mulheres que ignoram seu status sorológico para o HIV, como também as possibilidades de prevenção da transmissão verti- 
cal, não sendo raras as situações em que as mulheres deparam-se com a sua soropositividade no pré-natal, no parto e no pós-parto.

Investigar as derivações sociais e culturais em relação ao gênero e à presença do HIV na vida das mulheres é alvo de interesse, segundo objetivos de alguns estudos: Compreender o impacto que a infecção pelo HIV vem tendo sobre a vida de milhares de mulheres, particularmente no que tange a um aspecto tão fundamental da vivência feminina, como o é a maternidade HIV(7); Identificar atitudes e sentimentos entre mulheres grávidas HIV positivas ${ }^{(8)}$; Estudar, entre mulheres HIV positivas, os sentimentos associados à maternidade e à orfandade, a partir do conhecimento de sua condição sorológica ${ }^{(9)}$.

\section{- Segunda rubrica de análise: A organização programática}

A análise da vulnerabilidade à infecção pelo HIV aborda três dimensões: a vulnerabilidade individual, a social e a programática ${ }^{(10)}$. A vulnerabilidade programática, por sua vez, é definida através dos três principais elementos de prevenção identificados pela OMS: 1) informação e educação; 2) serviços sociais e de saúde; 3) não-discriminação das pessoas portadoras de HIV/Aids.

Destarte, plano programático refere-se à existência de ações institucionais especificamente voltadas para o problema da Aids, abrangendo aspectos como: a) compromisso das autoridades locais com o enfrentamento do problema; $b$ ) ações efetivamente propostas por estas autoridades; c) coalizão interinstitucional e intersetorial (saúde, educação, bemestar social, trabalho) para atuação específica; d) planejamento das ações; e) gerenciamento dessas ações; f) capacidade de resposta das instituições envolvidas; g) financiamento adequado e estável dos programas propostos; h) continuidade dos programas; i) avaliação e retroalimentação dos programas, etc ${ }^{(10)}$. Os estudos que abordam a vulnerabilidade programática, apresentaram os seguintes objetivos: Entender as necessidades de assistência e cuidado a saúde reprodutiva do ponto de vista dos portadores e descrever a estigmatização e a conseqüente violação dos seus direitos presente nas atitudes dos profissionais de saúde e na normatização dos modelos assistenciais ${ }^{(11)}$; Identificar em relatos de muIheres usuárias de drogas ilícitas e soropositivas para HIV, alguns elementos subsidiários ao desenvolvimento de Programas de Prevenção e Orientação em DST/Aids dirigidos para esse segmento social ${ }^{(12)}$.

- Terceira rubrica de análise: A vida cotidiana das mulheres com HIV/Aids

Com a evolução do tratamento e a disponibilização da terapia anti-retroviral, cada vez mais as pessoas com HIV podem manter-se saudáveis por muitos anos. Entretanto a existência de equívocos na sociedade sobre HIV/Aids e as formas de transmissão resultam em uma vida cercada de estigmas, que quase sempre se torna extremamente estressante e difícil.
Mulheres com HIV/Aids podem deparar-se com hostilidade e rejeição, mesmo das pessoas mais próximas. Elas ainda correm o risco de perder o emprego, suas famílias ou relações sociais importantes; e, imersas neste contexto, a dificuldade em falar sobre o diagnóstico e expressar a sexualidade torna-se uma constante.

A partir da vivência das mulheres com HIV/Aids, as pesquisas analisadas fornecem subsídios que permitem reflexões acerca da necessidade de transformações sociais e culturais em relação ao enfrentamento do estigma, o que pode ser observado nos objetivos: Categorizar e descrever fontes de estresse cotidianas de mulheres portadoras do vírus da imunodeficiência humana ${ }^{(13)}$; Avaliar a qualidade de vida entre mulheres portadoras de HIV/Aids ${ }^{(14)}$; Identificar e descrever estratégias de enfrentamento de Mulheres com HIV/Aids ${ }^{(15)}$.

\section{Como o pesquisador olha}

- Primeira rubrica de análise: Abordagens metodológicas

Considera-se que a escolha metodológica para a realização de uma pesquisa pode demonstrar como o pesquisador tenta explicar determinado fenômeno, e, pelos caminhos eleitos para fazer-se a explicação, reconhecer a compreensão do método utilizado e a coerência na aplicabilidade deste, para o alcance dos objetivos. Deste modo, um método se justifica e se estabelece à medida que, por seu intermédio, obtenha-se a aproximação de um objeto através da iluminação de um ou alguns de seus aspectos, aproximação esta que viabiliza uma melhor apreensão da realidade estudada, produzindo, inclusive, um conhecimento capaz de transformá-la(16).

Por definição, as abordagens qualitativa e quantitativa em pesquisa encerram conjuntos de práticas interpretativas, denominados métodos, que, em tese, não se prendem a um único campo do conhecimento, entendido este como área fronteiriça de manifestação dos processos de produção científica ${ }^{(17)}$.

Das pesquisas analisadas, sete utilizaram abordagem qualitativa ${ }^{(4,6,8-9,11,18-19)}$, cinco foram quantiqualitati$\operatorname{vas}^{(7,12-13,15,20)}$ e dois estudos foram quantitativos ${ }^{(5,14)}$.

Os estudos quantitativos têm como campo de práticas e objetivos trazer à luz dados, indicadores e tendências observáveis. Devem ser utilizados para abarcar, do ponto de vista social, grande aglomerado de dados, de conjuntos demográficos, por exemplo, classificando-os e tornandoos inteligíveis através de variáveis ${ }^{(21)}$.

No contexto da abordagem qualitativa aplicada às $\mathrm{Ci}$ ências da Saúde, emprega-se comumente a concepção trazida das Ciências Humanas, ou seja, busca-se entender o significado individual ou coletivo do fenômeno, e não apenas estudar o fenômeno em si. Ao transferir-se a concepção para a Saúde, torna-se indispensável o conhecimento sobre o que fenômenos como a doença e a vida representam para as pessoas.
Conflitos e sentimentos de mulheres portadoras de HIVIAids: um estudo bibliográfico Botti ML, Waidman MAP, Marcon SS, Scochi MJ 
Destarte, para o contexto das Ciências do Homem e da Saúde, transcreve-se inicialmente uma definição genérica de métodos qualitativos apresentada por dois sociólogos e habitualmente citada na literatura: Os pesquisadores qualitativistas estudam as coisas em seu setting natural, tentando dar sentido ou interpretando fenômenos nos termos das significações que as pessoas trazem para estes ${ }^{(22)}$.

A análise qualitativa pode não chegar a quantificar e, por outra parte, nada exclui que a análise quantitativa implique a necessidade de novas análises qualitativas. A contraposição entre qualidade e quantidade torna-se, portanto, matizada, e a integração, inevitável ${ }^{(17)}$.

- Segunda rubrica de análise: As teorias que fundamentam os discursos

As teorias devem envolver princípios e conceitos coerentes com a pesquisa ou trabalho que fundamentam. Assim, o referencial teórico deve ser compatível com o tratamento do problema e com o raciocínio desenvolvido. Encontrou-se nos trabalhos analisados a utilização de teorias distintas que buscaram elucidar as temáticas pesquisadas, as quais podem ser agrupadas em duas abordagens principais.

A primeira dessas abordagens vincula-se à temática pesquisada - o além-corpo físico. Identificou-se que os referenciais teóricos utilizados emanam das ciências humanas, como a psicologia social, a psicanálise e a sociologia, e foram: Teoria de crise e processo de solução de problemas ${ }^{(18)}$; Eventos estressantes ${ }^{(13)}$; Modos de enfrentamento de problemas $^{(15,20)}$; Mecanismos de defesa ${ }^{(9)}$; Perspectiva pós-estruturalista dos estudos culturais, fundamentada principalmente nas contribuições de Michel Foucault - usando a alegoria da colcha ${ }^{(19)}$ e Sexualidade ${ }^{(6)}$.

A segunda abordagem refere-se às questões de gênero, principalmente no que a tange à vulnerabilidade da mulher em relação à transmissão do HIV e adoecimento pela Aids. Para tanto, os referenciais utilizados foram: Subjetividades femininas ${ }^{(4)}$; Gênero e estigmatização(11); Abordagens de vulnerabilidade e gênero(8); Conceito materialista histórico dialético e o feminismo marxista $^{(7)}$; Qualidade de vida e mulheres com HIV/Aids ${ }^{(14)}$ e $O$ conceito de vulnerabilidade à infecção pelo HIV ${ }^{(5)}$.

Gênero pode ser entendido como uma forma de ideologia, suas concepções constroem-se disseminadamente na sociedade, ocorrendo a partir das diferentes narrativas vivenciadas. A preocupação com processos relacionados ao gênero justifica-se pelo fato de que esses influenciam o comportamento, os pensamentos e os sentimentos dos indivíduos, afetam as interações sociais e ajudam a determinar a estrutura das instituições sociais ${ }^{(23)}$.

\section{O que o olhar do pesquisador identifica}

Pesquisar é, antes de tudo, inquietar-se, é questionar a realidade procurando respostas muitas vezes temporárias. Ao acionar as respostas, novas inquietações surgem e engendram-se, sendo necessária a busca por novas respostas e explicações. Nesse processo, o pesquisador busca, a princípio, parcerias intelectuais e teóricas, colocando a teoria num lugar de destaque; porém o objeto só se desvela na interface entre o referencial teórico e a realidade encontrada no campo de pesquisa ${ }^{(24)}$.

A diversidade problemática encontrada no mundo feminino parece ser ainda maior ao deparar-se com a Aids. Alguns trabalhos descrevem o contexto deste encontro como: crises $^{(18)}$; estresse ${ }^{(13)}$; exclusões ${ }^{(4)}$; abandono pela família $^{(11)}$; prejuízo na qualidade de vida(14).

Além dos diversos problemas presentes na realidade vivenciada pelas mulheres com Aids, destaca-se a preocupação dos pesquisadores em verificar a função social da mulher modificada pela Aids, seja pelas estratégias de enfrentamento de mulheres com HIV/Aids ${ }^{(15,20)}$, seja pelas atitudes e sentimentos entre mulheres grávidas HIV positi$\operatorname{vas}^{(8)}$, influenciadas por questões profundas em relação $a$ ser mãe e não poder amamentar, á possibilidade de o filho ser soropositivo ${ }^{(8)}$, ou ainda à necessidade de planejar-se a orfandade do filho ${ }^{(9)}$.

\section{O olhar para além do corpo físico}

Os subsídios oferecidos pela literatura da área de saúde em relação aos conflitos e sentimentos das mulheres portadoras de HIV/Aids que podem direcionar o olhar para além do corpo físico destas mulheres apontam para a perspectiva do cuidado integral: Oferecer cuidados que integrem todos os momentos assistenciais ${ }^{(13)}$; A gravidez e o HIV demandam uma abordagem integral à mulher soropositiva: incorporar a sexualidade com uma perspectiva de gênero, promoção dos direitos humanos, tais como os diretos sexuais e reprodutivos ${ }^{(8)}$.

O cuidado passa, então, a ser pensado como meio para a manutenção ou reinclusão social, adotando a cidadania como um eixo norteador. A noção de cuidado social apresenta-se como uma forma de cuidado com a saúde, contrapondo-se aos mecanismos de exclusão e estigmatização ${ }^{(25)}$. Incentivar grupos de apoio emocional; Criar grupos de apoio aos familiares e aos parceiros; Discutir projetos de geração de renda; Obrigatoriedade ética e constitucional de promoção dos direitos reprodutivos ${ }^{(8)}$.

\footnotetext{
Com o envolvimento das famílias desde o momento do diagnóstico, a busca dessas mulheres para a adesão ao tratamento e a desmistificação do preconceito para o problema, torna-se mais fácil. Quando associamos o paciente, seus familiares e a equipe que presta assistência constroemse um processo terapêutico, no qual todos passam a ser responsável pelo acompanhamento dessas mulheres ${ }^{(11)}$.
}

O cuidado considerado integralmente envolve também a prevenção, ou seja, as formas programáticas, campanhas e informações devem ser capazes de atingir a singularidade dos indivíduos. As experiências de prevenção que vêm ocorrendo nos centros especializados em atendimento aos portadores do HIV raramente incorporam a compreensão dos aspectos socioculturais que possam ampliar vulnera- 
bilidade ao HIV e ao adoecimento. Os serviços continuam basicamente organizados para dar conta dos fatos biomédicos e da educação centrada nas vias de transmissão e na promoção dos instrumentos de proteção (preservativos, abstinência, seringas descartáveis etc.) ou no controle clínico da infecção e da adesão(24).

Demonstrando interesse em rever as formas das abordagens programáticas, alguns pesquisadores destacaram a importância da prevenção como forma de cuidado e desenvolvimento da cidadania:

A prevenção do HIV entre as mulheres deveria incluir também, além das estratégias de repasse de informações e de cuidados à saúde sexual e reprodutiva, estratégias de fortalecimento individual, reforço da auto-estima e estímulo à autonomia de uma forma geral(8).

Na perspectiva de um enfrentamento diferenciado e responsável em relação à saúde sexual e reprodutiva, verifica-se a indicação dos pesquisadores em destacar a necessidade de os profissionais de saúde entenderem as questões de gênero.

A dimensão das relações de gênero e do respeito à diversidade nas várias opções sexuais tem sido incorporada em muitas ações de prevenção, mas gênero ainda continua sendo pensado no singular, no feminino, como sinônimo de opressão feminina; não se aprofunda, nas ações de prevenção, o lidar com o impacto das relações de gênero no aumento da vulnerabilidade dos homens ${ }^{(24)}$. Desmistificar $a$ imagem da nova mulher e revelar como a ideologia de gênero obscurece, no capitalismo, o aprofundamento da exploração do trabalho produtivo e reprodutivo das mulheres da classe trabalhador ${ }^{(7)}$. Desnaturalizar a experiência da maternidade, mostrando como as condições para se ter e criar filhos são socialmente diferenciadas e desiguais ${ }^{(11)}$.

A transformação do profissional de saúde é esperada e imprescindível. O olhar limitado define condutas que desvalorizam a influência das estruturas socioeconômicas e culturais. Os consensos sobre como medicar os pacientes, rapidamente passados numa atitude receitadora de modelos prontos de como se comportar, ou o marketing de preservativos pago com dinheiro público (e não pela indústria que lucra com eles) não têm sido suficientes para produzir as mudanças que ainda são necessárias para que resultados significativos em relação ao cuidado integral, além do corpo físico, sejam alcançados ${ }^{(24)}$.

Algumas das pesquisas em estudo demonstraram a preocupação com esse cenário, como poder ser observado pelos seguintes trechos das obras:

[...] identificar a atualização da ideologia médica no campo reprodutivo; no caso da gravidez HIV+, esta se evidencia através da missão de salvar bebês, reproduzindo a ideologia de gênero que naturaliza as mulheres em seu papel materno ${ }^{(7)}$;

[...] o aporte de instrumentalização profissional e metodologias diferentes são necessários, no sentido de permitir diferentes aproximações em relação ao objeto de estudo, favorecendo a prática profissional e a produção de conhecimento(7);
Aprofundar as perguntas, atravessar os espelhos, transitar entre os espaços, rompendo binarismos, a rigidez das identidades, atravessando os jogos de poder/saber/verdade ${ }^{(19)}$;

Identificar as contradições e conflitos..., o que possibilita aos sujeitos sociais re-significar suas representações, experiências e práticas, profissionais e de vida, o que aponta para a possibilidade de transformações no modelo e nas práticas assistenciais relacionadas à saúde ${ }^{(7)}$.

As representações sociais dos soropositivos, homens e mulheres, estão dimensionadas em dois eixos, o objetivo e o subjetivo e esta característica pode ser explicada pela diferença de gênero, que influencia a percepção e o comportamento diante da vida ${ }^{(26)}$. Por exemplo, entre os homens há um predomínio de elementos objetivos, ou seja, a Aids se mostra como uma doença que causa medo, acarreta algumas limitações e, exige um novo recomeço de vida, prescindindo apoio. Já no grupo de mulheres há um predomínio de elementos subjetivos, com a Aids sendo representada como uma doença envolta em preconceito, que acarreta muito sofrimento e para a qual se busca uma esperança de saúde. A morte é vista, pelas mulheres, como terrível, premeditada, lenta, mobilizadora do medo, e discriminadora ${ }^{(26)}$.

O sofrimento de uma forma geral, que envolve o medo, o preconceito, o abandono, as diferenças entre gênero, a culpa e a exclusão ainda são constantes entre os portadores de HIV/Aids, por isso, é preciso encontrar estratégias para auxiliá-los e às suas famílias em seus processos de enfrentamento, aceitação e naturalização da situação. É preciso que os profissionais demonstrem preocupação com os aspectos não biológicos que interferem na cadeia de transmissão da doença e convivência com a mesma, pois os aspectos psíquicos, emocionais e sociais da epidemia são fontes de grande sofrimento para o portador. É claro que com os benefícios adquiridos com o controle e prolongamento da vida, a perspectiva do portador torna-se diferente demonstrando a necessidade de buscar e encontrar estratégias que proporcionem a essas pessoas uma vida com maior qualidade, pois os aspectos emocionais e psíquicos influenciam na qualidade da saúde das pessoas ${ }^{(27)}$. Apesar da evolução terapêutica e de seu reflexo direto na reinterpretação da Aids, observa-se, ainda hoje, que ela continua sendo associada à morte e a todo o sofrimento que lhe é pertinente, desde a sua descoberta.

\section{CONSIDERAÇÕES FINAIS}

O presente artigo identificou respeitáveis contribuições apresentadas pela produção científica da área de saúde sobre os conflitos e sentimentos das mulheres portadoras de HIV/Aids, as quais permitem subsidiar um olhar para além do corpo físico.

As pesquisas encontradas, apesar de escassas, demonstraram preocupações coerentes, especialmente ao tratarse das dimensões ética, saúde reprodutiva e direitos humanos. Apontaram a necessidade de abordagens socioculturais que considerem temáticas imprescindíveis para a compreensão da Aids e dos vários sentidos a ela atribuí-
Conflitos e sentimentos de mulheres portadoras de HIVIAids: um estudo bibliográfico Botti ML, Waidman MAP, Marcon SS, Scochi MJ 
dos, como: o enfoque de vulnerabilidade, a ideologia social de gênero, a promoção da auto-estima, o exercício de cidadania.

Ao refletir sobre os achados, verificou-se que o paradigma científico baseado nas abordagens biologistas, com

\section{REFERÊNCIAS}

1. Cervo AL, Bervian PA. Metodologia científica. 5a ed. São Paulo: Prentice Hall; 2002.

2. Pádua EMM. Metodologia da pesquisa: abordagem teóricoprática. 9a ed. Campinas: Papirus; 2003.

3. Bardin L. Análise de conteúdo. Lisboa: Edições 70; 1994.

4. Alves RN, Kovács MJ, Stall Ron PV. Fatores psicossociais e a infecção por HIV em mulheres, Maringá, PR. Rev Saúde Pública. 2002;36(4):32-9.

5. Sanches KRB. A aids e as mulheres jovens: uma questão de vulnerabilidade [tese]. Rio de Janeiro: Escola Nacional de Saúde Pública; Fundação Oswaldo Cruz; 1999.

6. Camargo MGB. A Aids e a constituição do feminino [dissertação]. Campinas: Faculdade de Educação, Universidade Estadual de Campinas; 2004.

7. Barbosa RHS. Mulheres, reprodução e aids: as tramas da ideologia na assistência à saúde de gestantes HIV+ [tese]. Rio de Janeiro: Escola Nacional de Saúde Pública, Fundação Oswaldo Cruz; 2001.

8. Feracin JCF. Atitudes e sentimentos das mulheres que vivenciaram a gravidez e a soropositividade ao vírus HIV [dissertação]. Campinas: Faculdade de Ciências Médicas, Universidade Estadual de Campinas; 2002.

9. Hebling EM. Mulheres soropositivas para HIV: sentimentos associados à maternidade e a orfandade [tese]. Campinas: Faculdade de Ciências Médicas, Universidade Estadual de Campinas; 2005.

10. Mann JM, Tarantola DJM, Netter TW. Aids in the world: the global Aids policy coalition. Cambridge: Harvard University Press; 1992. .

11. Paiva V, Segurado A, Felipe EV, Santos N, Lima TN. Sem direito de amar? A vontade de ter filhos entre homens (e mulheres) vivendo com o HIV. Psicol USP. 2002;13 (2):105-33.

12. Franco FG, Figueiredo MAC. Aids, drogas e "ser mulher". Relatos de mulheres soropositivas para o HIV. Rev Med. 2004;37(1):106-16.

13. Tunala LG. Fontes cotidianas de estresse entre mulheres portadoras de HIV. Rev Saúde Pública. 2002;36 Supl 4:24-31.

14. Galvão MTG, Cerqueira ATAR, Marcondes-Machado J. Avaliação da qualidade de vida de mulheres com HIV/Aids através do HAT-QoL. Cad Saúde Pública. 2004; 20(2):430-7. olhar apenas para o corpo físico, não é capaz de dar conta da complexidade do fenômeno social da Aids, e neste aspecto vale ressaltar sua conexão com o paradigma do cuidado, pois estes dois paradigmas parecem ser complementares.
15. Seidl EMF. Enfrentamento, aspectos clínicos e sociodemográficos de pessoas vivendo com HIV/Aids. Psicol Estud. 2005;10(3):421-9.

16. Lima Filho EC. Debate sobre o artigo de Minayo \& Sanches. Cad Saúde Pública 1993;9(3):251-2.

17. Landin FLP, Lourinho LA, Lira RCM, Santos ZMSA. Uma reflexão sobre as abordagens em pesquisa com ênfase na integração qualitativo-quantitativo. Rev Bras Promoc Saúde. 2006; 19(1):53-8.

18. Freitas MRI, Gir E, Furegato ARF. Sexualidade do portador do vírus da imunodeficiência humana (HIV): um estudo com base na teoria da crise. Rev Lat Am Enferm. 2002;10(1):70-6.

19. Cruz EF. Espelhos d'Aids: infâncias e adolescências nas tessituras da Aids [tese]. Campinas: Faculdade de Educação, Universidade Estadual de Campinas; 2005.

20. Faria JB, Seidl EMF. Religiosidade, enfrentamento e bem-estar subjetivo em pessoas vivendo com hiv/aids. Psicol Estud. 2006;11(1):155-64.

21. Minayo MC, Sanches O. Quantitativo - Qualitativo: oposição ou complementaridade? Cad Saúde Pública. 1993;9(3): 239-62.

22. Denzin NK, Lincoln YS. Introduction: the discipline and practice of qualitative research. In: Denzin NK, Lincoln YS, editores. Handbook of qualitative research. London: Sage; 2000. p. 1-29.

23. Maffioletti VLR, Loyola CMD, Nigri F. Os sentidos e destinos do cuidar na preparação dos cuidadores de idosos. Cienc Saúde Coletiva. 2006;11(4):1085-92.

24. Okada A, Santos EO, Okada S. Mapeando informação, trilhando e construindo redes de significados: notas sobre uma experiência de pesquisa e docência em educação online. Rev FAEEBA. 2005;14(23):73-90.

25. Paiva V. Sem mágicas soluções: a prevenção e o cuidado em HIV/ AIDS e o processo de emancipação psicossocial. Interface Comun Saúde Educ. 2002;6(11):25-38.

26. Castanha AR, Coutinho MPL, Saldanha AAW, Ribeiro CG. A avaliação da qualidade de vida em soropositivos para o HIV. Estud Psicol (Campinas). 2007;24(1):23-31.

27. Andrade BB. Marcas no corpo, marcas na alma: as relações familiares de mulheres HIV positivas infectadas por seus maridos [dissertação]. Maringá: Departamento de Enfermagem, Universidade Estadual de Maringá; 2007. 


\section{ANEXO}

Quadro 1 - Aspectos analisados nas pesquisas incluídas no estudo - Maringá, PR - 2006

\begin{tabular}{|c|c|c|c|}
\hline Identificação & $\begin{array}{l}\text { Alves RN, Kovács MJ, } \\
\text { Stall Ron PV. Fatores } \\
\text { psicossociais e a infecção } \\
\text { por HIV em mulheres, } \\
\text { Maringá, PR. Rev Saude } \\
\text { Publica. 2002;36(4):32-39 }\end{array}$ & $\begin{array}{l}\text { Camargo MGB. A Aids e a } \\
\text { constituição do feminino } \\
\text { [dissertação]. Campinas: } \\
\text { Faculdade de Educação da } \\
\text { Universidade Estadual de } \\
\text { Campinas; 2004. }\end{array}$ & $\begin{array}{l}\text { Hebling EM. Mulheres } \\
\text { soropositivas para HIV: } \\
\text { sentimentos associados à } \\
\text { maternidade e a orfandade } \\
\text { [tese]. Campinas: Faculdade } \\
\text { de Ciências Médicas da } \\
\text { Universidade Estadual de } \\
\text { Campinas; } 2005 \text {. }\end{array}$ \\
\hline Objetivos & $\begin{array}{l}\text { Descrever como as } \\
\text { mulheres portadoras do } \\
\text { HIV percebem sua } \\
\text { vulnerabilidade na } \\
\text { provável época da } \\
\text { infecção e compreender as } \\
\text { dificuldades de prevenção } \\
\text { da transmissão sexual do } \\
\text { HIV antes e depois do } \\
\text { diagnóstico. }\end{array}$ & $\begin{array}{l}\text { Percepção do risco de infecção } \\
\text { em mulheres infectadas pelo } \\
\text { HIV. }\end{array}$ & $\begin{array}{l}\text { Estudar, entre mulheres HIV } \\
\text { positivas, os sentimentos } \\
\text { associados à } \\
\text { maternidade e à orfandade, a } \\
\text { partir do conhecimento de sua } \\
\text { condição sorológica. }\end{array}$ \\
\hline $\begin{array}{l}\text { Referencial } \\
\text { Metodológico }\end{array}$ & $\begin{array}{l}\text { Estudo exploratório } \\
\text { (CHIZZOTTI, 1991). }\end{array}$ & $\begin{array}{l}\text { Pesquisa qualitativa } \\
\text { (Foucault). }\end{array}$ & $\begin{array}{l}\text { Estudo qualitativo } \\
\text { Patton (1990). }\end{array}$ \\
\hline $\begin{array}{l}\text { Referencial } \\
\text { Teórico }\end{array}$ & $\begin{array}{l}\text { Subjetividade feminina e } \\
\text { soropositividade } \\
\text { (KNAUTH, 1999) }\end{array}$ & $\begin{array}{l}\text { Sexualidade (Foucault e } \\
\text { autores pós - estruturalistas). }\end{array}$ & $\begin{array}{l}\text { Mecani smos de defesa do ego } \\
\text { contra idéias ou sentimentos } \\
\text { dolorosos ou insuportáveis } \\
\text { (Anna Freud, 1974). }\end{array}$ \\
\hline $\begin{array}{l}\text { Situação } \\
\text { Encontrada }\end{array}$ & Exclusões & Fidelidade, confiança e crença. & Maternidade e Orfandade \\
\hline $\begin{array}{l}\text { Fatores } \\
\text { Associados }\end{array}$ & $\begin{array}{l}\text { Dificuldades pessoais } \\
\text { Dificuldades simbólicas } \\
\text { Dificuldades econômicas }\end{array}$ & Relacionamento amoroso. & $\begin{array}{l}\text { Maternidade: Direito e } \\
\text { sentimento de ser mãe, não } \\
\text { poder amamentar e o bebê } \\
\text { nascer soropositivo. } \\
\text { Orfandade: Planejamento para } \\
\text { situações de doença ou óbito } \\
\text { materno e sentimento em } \\
\text { relação à orfandade do fillho. }\end{array}$ \\
\hline Respostas & $\begin{array}{l}\text { Os programas de } \\
\text { prevenção do HIV devem } \\
\text { considerar aspectos } \\
\text { psicológicos, } \\
\text { socioeconômicos e } \\
\text { culturais. Usar abordagens } \\
\text { psicoeducativas. }\end{array}$ & $\begin{array}{l}\text { Apesar dos pactos do casal } \\
\text { ser em fluidos e passíveis de } \\
\text { mudanças, a mulher procura } \\
\text { dar um significado ao seu } \\
\text { território amoroso acreditando } \\
\text { e confiando na fidelidade do } \\
\text { Parceiro. }\end{array}$ & $\begin{array}{l}\text { Mecanismos, como os de } \\
\text { compensação, negação, } \\
\text { racionalização e projeção, } \\
\text { entraram em ação para } \\
\text { minimizar sentimentos } \\
\text { inconscientes de culpa. }\end{array}$ \\
\hline
\end{tabular}

